\title{
Antibiotic Sensitivity of Staphylococcus aureus and Staphylococcus epidermidis Isolated from Acne Patients
}

\author{
Ashfia Fatima Khan ${ }^{1}$, Humayera Kabir Hana ${ }^{1}$, Jakaria Sheak ${ }^{1}$ and Kohinur Begum ${ }^{2}$ \\ ${ }^{1}$ Department of Pharmacy, Primeasia University, Banani, Dhaka, Bangladesh, \\ ${ }^{2}$ Department of Pharmacy, ASA University Bangladesh, ASA Tower, Shyamoli, Dhaka-1207, Bangladesh.
}

Received: April 25, 2015; Accepted: June 07; 2015; Published (Web): July 21, 2015

\begin{abstract}
In this study, twenty five samples were collected from acne, ranging from 20 to 25 years old patients. The specimens were cultured on trypticase soy agar (TSA) plate. 25 suspected single colonies were isolated using mannitol salt agar. Isolates were identified by short biochemical tests such as catalase, coagulase, oxidase and Gram staining test. Five Staphylococcus aureus and eleven Staphylococcus epidermidis strains were identified. Antibiotic sensitivity of all strains was tested according to the Kirby-Bauer method using commercially available gentamicin, erythromycin, azithromycin, oxacillin, clindamycin and rifampicin discs. $100 \%$ of the isolates were sensitive to gentamicin and rifampicin. On the other hand, $93.75 \%$ isolates were sensitive to oxacillin, erythromycin and azithromycin and $81.25 \%$ isolates were sensitive to clindamicin. Minimum inhibitory concentration (MIC) of rifampicin and gentamicin was determined by test tube serial dilution method and it was found to be $4 \mu \mathrm{g} / \mathrm{ml}$ for both. Our results showed that both rifampicin and gentamicin are effective antibacterial agents for acne.
\end{abstract}

Key words: Antibiotic sensitivity, Staphylococcus aureus, Staphylococcus epidermidis, Acne.

\section{Introduction}

Acne is one of the most common skin disorders in youth, especially during the puberty often continuing until adulthood. It is characterized by the formation of open and closed comedones, papules, pustules, nodules and cysts which are present mostly on the face, upper back and chest. Prevalence of acne is about $70-87 \%$ in the world (Dreno and Poli, 2003). Teenagers are more susceptible to acne vulgaris due to diets consisting primarily of processed foods deficient in basic micro nutrients and balanced nutrients. Since a balanced diet is required to produce hormones and healthy skin, their skin is deprived of nutrition and is highly prone to developing severe acne. Studies have shown that most commonly bacteria associated with this disease are S. epidermidis, S. aureus, and Propionibacterium acnes. Although, it is not a serious threat to general health but it is one of the most socially and psychologically distressing skin conditions, especially for adolescents, results in diminished self esteem and social withdrawal due to embarrassment. The frequently prescribed antibiotics are tetracycline, erythromycin, gentamicin, rifampicin, doxycycline, and minocycline. Clindamycin, and trimethoprim or sulfamethoxazole are very effective, but are not used as first line drugs because of their potential side effects (Fanelli et al., 2011). Clindamycin and erythromycin are the topical antibiotics most frequently used for treating inflammatory acne (Gollnick et al., 2003). The prevalence of antibiotic resistant to acne causing bacteria is increasing and due to this bacterial resistance, combination of antibiotics with benzoyl peroxide or a topical retinoid are used for treatment of acne (Thiboutot et al., 2009). This study has been designed to determine the antibiotic sensitivity of bacteria obtained from acne patients.

\section{Materials and Methods}

Collection of bacterial samples: Samples were collected from 25 volunteers between the ages of 20-25 years and grown in TSA plate. In total, 25 suspected single colonies were isolated in mannitol salt agar by observing their characteristic colony morphology. Suspected colonies were identified by Gram straining and

Correspondence to: Kohinur Begum, E-mail: kohinur 025@yahoo.com 
short biochemical tests (MacFaddin, 2000; Bergey et al., 1994).

Catalase test: The catalase test was performed by using 3\% hydrogen peroxide. A drop of hydrogen peroxide (3\%) was placed on glass slide. Using a loop, the sample was added and mixed well. Presence of bubble or froth, indicated catalase positive and no bubble or froth indicated catalase negative. S. aureus ATCC 25923 and $E$. coli ATCC 25922 were used as positive and negative control, respectively.

Coagulase test: A slide coagulase test was performed using sheep plasma. Two drops of saline water was placed on the slide and inoculated the test sample and control. It was mixed with the test samples using a loop. A drop of sheep plasma was added on the inoculated saline drop and mixed well. The slide was rocked gently for 10 seconds. Clumping was observed in the plasma within 10 seconds indicated a positive test, where as for negative test, no clumping was observed. S. aureus ATCC 25923 and E. coli ATCC 25922 were used as positive and negative control, respectively.

Oxidase test: Oxidase test was performed by using an oxidizing agent $N, N, N^{\prime}, N^{\prime}$-tetramethyl-p-phenylenediamine (TMPD). An isolated colony from fresh culture plate was taken and placed onto filter paper soaked with TMPD. Color change was observed. Dark purple color appeared within 5 to 10 seconds indicated oxidase positive and no color change after 2 minutes indicated negative response for oxidase test. S. aureus ATCC 25923 and $E$. coli ATCC 25922 were used as negative and positive control, respectively.

Gram staining: Gram staining test was performed for all isolated strains according to the standard procedure. $S$. aureus ATCC 25923 and E. coli ATCC 25922 were used as positive and negative control, respectively.

Antibiotic sensitivity test: Mueller Hinton agar plates were used for antibiotic sensitivity test. All isolates were used for testing antibiotic sensitivity by Kirby-Bauer method. A sterile swab was used to spread the sample uniformly on the surface of the medium. Antibiotic disc (Hi- media) of gentamicin $(10 \mu \mathrm{g})$, erythromycin $(15 \mu \mathrm{g})$, azithromycin $(30 \mu \mathrm{g})$, oxacillin $(1 \mu \mathrm{g})$, clindamycin $(2 \mu \mathrm{g})$ and rifampicin $(5 \mu \mathrm{g})$ were placed onto the inoculated medium and incubated at $37^{\circ} \mathrm{C}$ for $24 \mathrm{~h}$. Diameter of the zone of inhibition around each antibiotic disc was recorded in millimetres to determine the sensitivity or resistant categories according to the standard chart of $\mathrm{Hi}$ media.

Determination of minimum inhibitory concentration: Gentamicin and rifampicin were found to be most effective antibacterial agents and were selected for MIC determination. MIC was determined by the test tube serial dilution method (Andrews, 2000). S. aureus ATCC 25923 was used as the positive control. Fresh culture of test samples and controls were prepared. $10 \mathrm{mg} / \mathrm{ml}$ solution of gentamycin and rifampcin were prepared with sterile distilled water. Eight test tubes were labeled as 1, 2, 3, 4, 5, 6, 7, 8 and one set as control and one only as medium. 4 $\mathrm{ml}$ of nutrient broth media was poured into $1^{\text {st }}$ test tube, and $2 \mathrm{ml}$ in rest of the test tubes. From stock solution, 25.6 $\mu \mathrm{l}$ solution $(64 \mu \mathrm{g} / \mathrm{ml})$ was added to $1^{\text {st }}$ test tube. From $1^{\text {st }}$ test tube $2 \mathrm{ml}$ was transferred into $2^{\text {nd }}$ test tube and from $2^{\text {nd }}$ test tube, $2 \mathrm{ml}$ was transferred to $3^{\text {rd }}$ test tube. So the concentration of each test tube decreased by 2 -fold. This 2-fold dilution was performed till $8^{\text {th }}$ test tube. $100 \mu$ of bacterial broth sample was added into each test tube except medium. All test tubes containing antibiotic with bacteria were incubated for $24 \mathrm{~h}$ at $37^{\circ} \mathrm{C}$ temperatures. Clear solution in test tube indicated no growth of organism, where, an opaque test tube indicated the growth of organism.

\section{Results and Discussion}

The previous studies have shown that both aerobic and anaerobic bacteria could be associated with acne vulgaris (Ross et al., 2001). Healthy skin pores are colonized by $P$. acnes, a relatively slow growing aerotolerant, anaerobic, gram positive bacterium, while nonpore resistant S. epidermidis, S. aureus, and Micrococcus sp. are sometime found from the culture of the follicular material (Silverberg and Weinberg, 2001). These organisms aggravate the inflammatory reaction that may be initiated by increase in sebum production, free fatty acids from sebum and abnormal keratinization of the sebaceous canal. In this study, twenty five samples were collected from pus cell of nodulocystic and pustular acne of volunteers (Figure 1). In total, 25 suspected single colonies were isolated in TSA plate by observing their characteristic colony morphology (Figure 2). Out of 25 isolates, five $S$. aureus and eleven $S$. epidermidis strains 
were identified by using selective media, short biochemical tests and Gram staining. All of the 25 isolates were catalase positive, six isolates were positive for coagulase test indicating the presence of $S$. aureus whereas eleven isolates were negative for coagulase indicating $S$. epidermidis positive. The result of biochemical and Gram staining tests are shown in table 1.

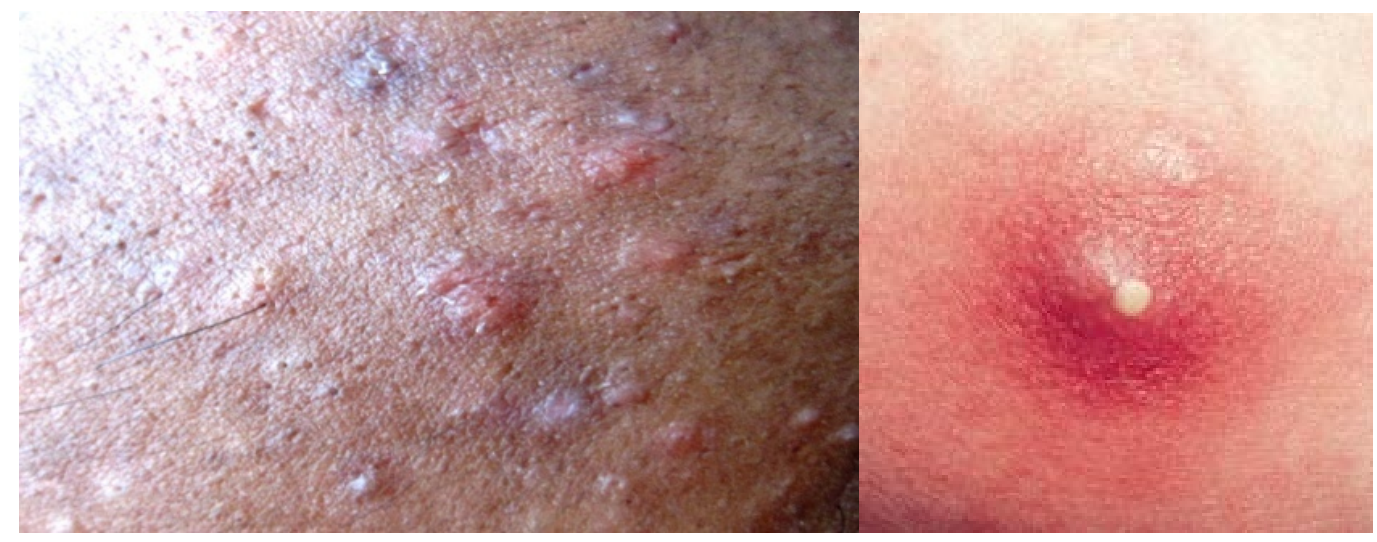

Figure 1. Site of sample collection.

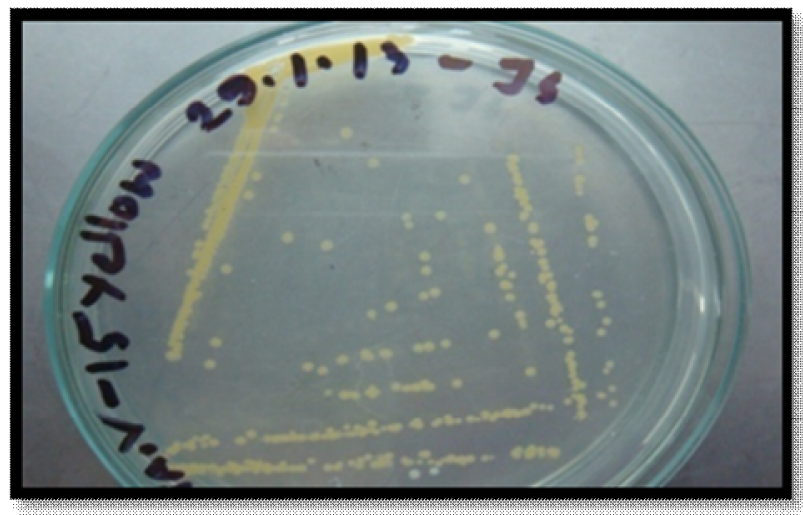

Figure 2. Isolated bacteria in TSA plate.

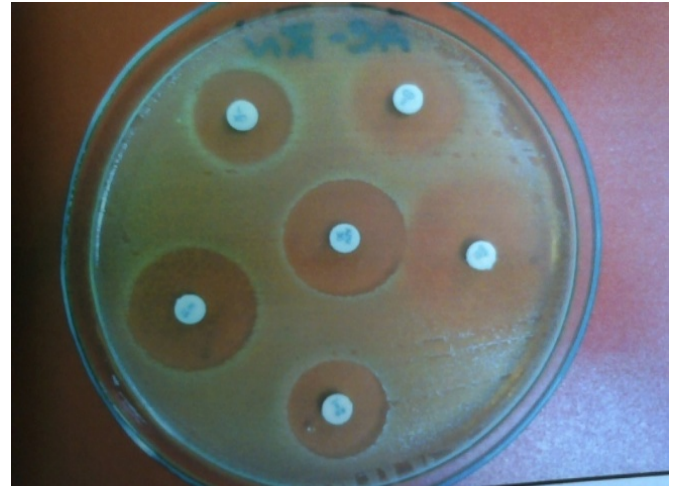

Figure 3. Zone of inhibition of antibiotic sensitivity test.

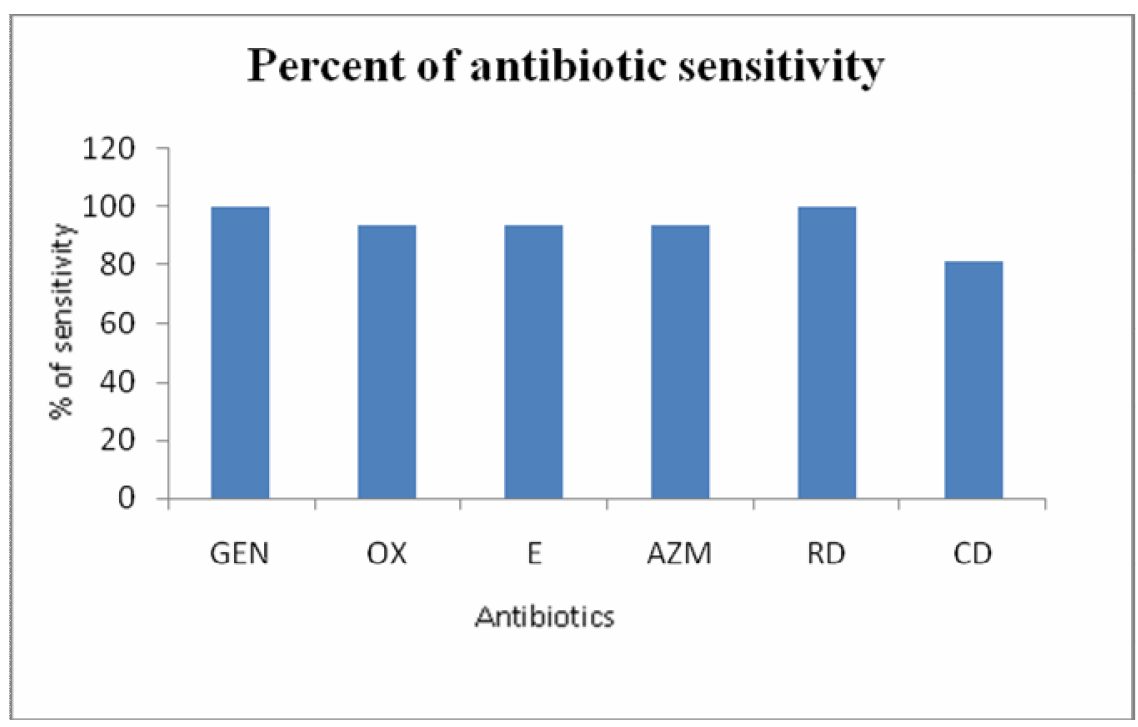

Figure 4. Percent antibiotic sensitivity against bacteria. 
Table1. Results of short biochemical and gram staining test.

\begin{tabular}{ccccc}
\hline Sample no & $\begin{array}{c}\text { Catalase } \\
\text { test }\end{array}$ & Coagulase test & Oxidase test & $\begin{array}{c}\text { Gram } \\
\text { staining }\end{array}$ \\
\hline AC-1 & + & + & - & + \\
AC-2 & + & - & - & + \\
AC-3 & + & - & - & + \\
AC-4 & + & - & + & + \\
AC-5 & + & + & + & + \\
AC-6 & + & - & - & + \\
AC-7 & + & - & + & + \\
AC-8 & + & + & - & + \\
AC-9 & + & + & - & + \\
AC-10 & + & + & - & + \\
AC-11 & + & - & - & + \\
AC-12 & + & + & - & + \\
AC-13 & + & + & + & + \\
AC-14 & + & + & + & + \\
AC-15 & + & + & - & + \\
AC-16 & + & + & - & + \\
AC-17 & + & - & - & + \\
AC-18 & + & - & - & + \\
AC-19 & + & - & + & + \\
AC-20 & + & + & + & + \\
AC-21 & + & + & + & + \\
AC-22 & + & - & + & + \\
AC-23 & + & + & + & + \\
AC-24 & + & - & + & + \\
AC-25 & + & + & + & + \\
S. aureus ATCC 25923 & + & + & + & + \\
S. epidermidis & + & - & + & + \\
E. coli ATCC 25922 & - & - & + & + \\
\hline
\end{tabular}

+ sign indicates positive result and - sign indicates negative result, NA= not applicable

Table 2. Results of minimum inhibitory concentration of gentamicin and rifampicin.

\begin{tabular}{|c|c|c|c|c|c|c|c|c|}
\hline \multirow[t]{2}{*}{ Sample no } & \multicolumn{8}{|c|}{ Concentration of rifampcin $(\mu \mathrm{g} / \mathrm{ml})$} \\
\hline & 64 & 32 & 16 & 08 & 04 & 02 & 01 & 0.5 \\
\hline AC-3 & - & - & - & - & - & + & + & + \\
\hline AC-9 & - & - & - & - & - & + & + & + \\
\hline \multirow{3}{*}{$\begin{array}{c}\text { S. aureus ATCC } \\
25923\end{array}$} & - & - & - & - & - & + & + & + \\
\hline & \multicolumn{8}{|c|}{ Concentration of gentamicin $(\mu \mathrm{g} / \mathrm{ml})$} \\
\hline & 64 & 32 & 16 & 08 & 04 & 02 & 01 & 0.5 \\
\hline $\mathrm{AC}-3$ & - & - & - & - & - & + & + & + \\
\hline AC-9 & - & - & - & - & - & + & + & + \\
\hline $\begin{array}{c}\text { S. aureus } \\
\text { ATCC } 25923\end{array}$ & - & - & - & - & - & + & + & + \\
\hline
\end{tabular}

+ sign indicates growth of organism and - sign indicates no growth of organism

Many medications are available for the management of acne. Antibiotic therapy has been integral part to the treatment of acne for many years. The widespread and long-term use of antibiotics has unfortunately led to the emergence of resistant bacteria (Tan and Tan, 2005).
Combination therapy consisting of a topical retinoid and an antibiotic is used as an effective method for the management of acne vulgaris (Hasanzadeh et al., 2008)). Recent advances in the pathogenesis of acne have led to the development of new therapeutic agents (James et al., 
2009). Long-term therapy with oral antibiotics is not only a threat to the development of the resistance to $P$. acnes and coagulase-negative staphylococci on the skin, $S$. aureus in the nares, and streptococci in the oral cavity (Rathi, 2011). However, it has been reported that in the bacterial flora of acne lesions, $P$. acnes and S. epidermidis were found to be sensitive to the antibiotics used in the treatment of acne. Rifampicin and tetracycline were found effective antibiotic against both of these species (Zaluga $e t$ al., 1996). In this study, antibiotic sensitivity test was done for all isolates. $100 \%$ of the isolates were sensitive to gentamicin and rifampicin, $93.75 \%$ were sensitive to oxacillin, erythromycin and azithromycin and 81.25\% were sensitive to clindamycin. Results of antibiotic sensitivity test showed in the figure 3 and 4 . MIC for both rifampicin and gentamicin was found to be $4 \mu \mathrm{g} / \mathrm{ml}$ as shown in table 2. Our results showed that both rifampicin and gentamycin are the most effective antibiotics for acne vulgaris. Better treatment can be achieved by using rifampincin and gentamycin or combination with other antibiotics

\section{References}

Andrews, J.M. 2000. Determination of minimum inhibitory concentrations. J. Antimicrob. Chemother. 48, 5-16.

Bergey, D.H., Holt, J.G., Krieg, N.R. and Sneath P.H.A. 1994. Bergey's Manual of Determinative Bacteriology ( $9^{\text {th }}$ ed.). Lippincott Williams and Wilkins. Brown (2012). Bensons Microbiological applications; laboratory manual in general Microbiology, short version, $12^{\text {th }}$ ed. McGraw-Hill, NY.

Dreno, B. and Poli, F. 2003. Epidemiology of acne. Dermatol. 206, 7-10.

Fanelli, M., Kupperman, E., Lautenbach, E., Edelstein, P.H. and Margolis, D.J. 2011. Antibiotics, Acne, and Staphylococcus aureus Colonization. Arch. Dermatol. 147, 917-921.
Gollnick, H., Cunliffe, W., Berson, D., Dreno, B., Finlay, A., Leyden, J.J., Shalita, A.R. and Thiboutut, D. 2003. Management of acne: a report from a global alliance to improve outcomes in acne. J. Am. Acad. Dermatol. 49, 1-37.

Hassanzadeh, P., Bahmani, M. and Mehrabani, D. 2008. Bacterial Resistance to antibiotics in acne vulgaris: an in vitro study. Indian J. Dermatol. 53, 122-124.

James, K.A., Burkhart, C.N. and Morrell, D.S. 2009. Emerging drugs for acne. Expert Opin. Emerg. Drugs. 14, 649-659.

MacFaddin, J.F. 2000. Biochemical tests for identification of medical bacteria. $3^{\text {rd }}$ ed. Philadelphia: Lippincott Williams and Wilkins. pp. 363-367.

Rathi, S.K. 2011. Acne vulgaris treatment: the current scenario. Indian J. Dermatol. 56, 7-13.

Ross, J.I., Snelling, A.M., Eady, E.A., Core, J.H., Cunliffe W.J. and Leyden, J.J. 2001. Phenotypic and genotypic characterization of antibiotic resistant Propionibacterium acne isolated from acne patients attending dermatology Clinics in Europe, Japan, USA and Australia. Br. J. Dermatol. 144, 225-227.

Silverberg, N.B. and Weinberg, J.M. 2001. Rosaceae and adult acne: a worldwide epidemic. Cutis. 68, 85.

Tan, A.W and Tan, H.H. 2005. Acne vulgaris: a review of antibiotic therapy. Expert Opin. Pharmacother. 6, 409-418.

Thiboutot, D., Gollnick, H., Bettoli, V., Dréno, B., Kang, S., Leyden, J.J., Shalita, A.R., Lozada, V.T., Berson, D., Finlay, A., Goh, C.L., Herane, M.I., Kaminsky, A., Kubba, R, Layton, A., Miyachi, Y., Perez, M., Martin, J.P., RamosE-Silva, M., See, J.A., Shear, N. and Wolf, J.J. 2009. New insights into the management of acne: an update from the Global Alliance to Improve Outcomes in Acne group. $J$. Am. Acad. Dermatol. 60, 1-50.

Zaluga, E., Giedrys-Kalemba, S. and Halasa, J. 1996. Bacterial flora of acne lesions in diagnostic material of the Microbiology and Immunology Department, Pomeranian Medical Academy (PAM) in Szczecin. Med. Dosw. Mikrobiol. 48, 55-59. 